microscope and the cooling process is continued until hoar frost is seen to form. An electrical thermometer, either thermojunction or resistance type, is embedded in the thimble and enables the temperature to be noted when the hoar frost is formed. In practice, a small deposit is allowed to form and the temperature then adjusted so that individual crystals are seen neither to grow nor to evaporate. The thimble can be warmed by means of a small heating coil.

In a modified design Dobson has arranged the indication to be done by means of a photo-electric cell. A beam of light is directed obliquely on to the face of the thimble and the light scattered by the hoar frost deposit is focused on to the cell. A constant reading on the microammeter of the photo-cell indicates a steady condition of the frost deposit.

Fitted to an aeroplane, the instrument has yielded most important results in the hands of $\mathrm{Mr}$. Brewer. Up to the base of the stratosphere, the frost-point temperature is usually only slightly below the air temperature, thus indicating a fairly high humidity. As soon as the stratosphere is reached the air temperature rises but the frost temperature falls even more rapidly than before. At a distance of $2 \mathrm{~km}$. within the stratosphere the frost point may be more than $35^{\circ} \mathrm{C}$. below the air temperature, corresponding to a relative humidity of the order of 1 per cent.

The radio sonde and wind-finding technique have given us information up to a height of about $18 \mathrm{~km}$. To reach still greater heights, use has been made of a very high velocity gun. The shell is filled with smoke composition, and the smoke cloud produced at burst can be followed by theodolites to give both the speed and direction of the wind. A systematic series of wind determinations has been made at a height of $30 \mathrm{~km}$., although greater altitudes may be attainable.

Observations extending from February 1944 to May 1945 have shown that the wind at $30 \mathrm{~km}$. is mainly westerly during winter and easterly during summer. Actually the direction lies between about south-west and north-west in the first case, and between north-east and south-east in the second case. The change-over takes place in about April and October. Over the period covered by the observations, the mean velocity in winter was $37 \mathrm{~m}$. per sec. and in summer about $12 \mathrm{~m}$. per sec. The greatest velocity observed was $66 \mathrm{~m}$. per sec. from a direction $285^{\circ}$ (true). This observed seasonal change in the wind at this level confirms a prediction made by the late Dr. F. J. W. Whipple from his study of the audibility of explosions at long distances. It is hoped that a full account of these wind measurements will be published shortly by Flight-Lieutenant Murgatroyd, the meteorological officer who has been associated with the work.

It will have been noted that most of the methods described above are concerned with increasing our knowledge of the conditions in the upper atmosphere. This is symptomatic of the whole trend of modern meteorology. It has now become possible to study the atmosphere in three dimensions as a matter of routine, instead of confining our attention to the phenomena occurring at ground-level. This new outlook constitutes the greatest advance made in meteorology in recent times.

We have, however, only just begun to use these now instruments and techniques, and there is every reason to believe that their continued employment will yield results of the greatest importance to the science of meteorology.

\section{DEVELOPMENT IN THE SCIENTIFIC INSTRUMENT INDUSTRY IN GREAT BRITAIN}

$T$ HE vital part played by scientific and technical research in the Second World War is recognized by everyone-radar, high-speed aircraft, magnetic mines, degaussing, Pluto, Fido, and now atomic energy, are only a few of the many achievements of science and engineering of which we now hear so much. Cabinet ministers and the Press have paid high tribute to such achievements and we are justified in hoping that there is a better future in store for scientific research in Great Britain.

It is important not to forget, however, that modern science cannot make satisfactory progress without an adequate supply of good scientific instruments. Not much more than a generation ago, scientific instruments as now understood scarcely existed. The equipment of university research laboratories was very poor indeed, judged by modern standards : a few reflecting galvanometers, voltmeters and ammeters, with possibly a vibration galvanometer and a Duddell or Einthoven oscillograph, were the main equipment of many electrical laboratories. Valves were not in common use until some time after the First World War. Cathode ray oscillographs, now almost as common as valves, came on the market in small numbers about twenty-five years ago.

The magnificent array of scientific instruments which are now manufactured in Great Britain is testimony to the vigorous growth of the scientific instrument industry during the past twenty or thirty years. During the war years 1939-45, the development has been most remarkable. Many in. struments previously in very short supply have reached the mass-production stage without loss of accuracy and reliability; some of the older measuring instruments have been modernized, and new designs have been produced to meet special war-time requirements. The necessities of a 'scientific war' have called for an outstanding display of ingenuity, both in the design and construction of scientific instruments.

A clear indication of the present state of develop. ment and importance of the industry was provided in the recent exhibition of scientific instruments organised by the Physical Society at the Imperial College of Science and Technology, South Kensington. In normal times the exhibition is held annually, but the War enforced a long break between the twenty. ninth exhibition held in January 1939, and the thirtieth held in January 1946. The abnormally long interval between these exhibitions, combined with the exceptional demands of war, served to reveal more clearly the remarkable progress made by the industry in this period. It is of interest to observe also that exhibits which once appeared in the Research Section of the exhibition now appear in the Industrial Section. As evidence of the national importance of the exhibition, it was opened by Sir Stafford Cripps, president of the Board of Trade. In his opening remarks he referred to the excellent achievements of the scientific instrument industry in Great Britain during the six years of war. Referring to mass production, he said, "instead of debasing their standards by introducing volume production, they have carried into that mass production the skill and accuracy which they had long cultivated in their specialized 
and small-quantity productions". He emphasized that the scientific man must be duly and properly equipped for his work. War-time research laboratories and equipment put to shame the accommodation and facilities provided in pre-war days in universities and research centres. After referring to the necessity for improving the status of men of science and for providing them with proper facilities and accommodation for research, he said, "Finally, there is the allimportant matter with which this exhibition is concerned. We cannot afford to be dependent upon others for the instruments necessary for our education of scientists or for the research work which they do, nor indeed, for all those many testing instruments which are to-day part and parcel of every up-to-date industrial concern. It is essential that we should have and maintain in this country a pre-eminent scientific instrument manufacture both for our own use and to help to supply those many other countries who cannot themselves afford to set up such manufactures." A full report of Sir Stafford Cripps' address appears in the January number of the Proceedings of the Physical Society.

The very bulky catalogue of the exhibition, extending to about 370 pages, well illustrated and printed on good quality paper, is in itself a sufficient proof of the importance attached to the scientific instrument industry. Even the Controller of Paper must have been convinced of that! This catalogue is a valuable work of reference, containing as it does a reference to, and in most cases a brief description, and maker's name of, the more recent scientific instruments manufactured in Great Britain. The exhibition, as usual, was conveniently divided into two sections: (a) a Research and Educational Section; and (b) a Trade Section. The former contained exhibits and demonstrations from thirty-five university, industrial, research association, Government and private laboratories, while the latter contained representative exhibits and demonstrations from one hundred and twelve firms manufacturing scientific instruments, and five publishers of scientific literature.

Owing to the limitations of available space at the Imperial College, the Exhibition Committee of the Physical Society had found it necessary to refuse permission for a number of firms to exhibit and to restrict severely the amount of space allotted to each of the exhibitors accepted. This fact in itself points to the rapid growth of the industry, and indicates also that the exhibition has outgrown the proportions originally envisaged by the Physical Society. If the growth of the industry continues at anything like its present rate, it will be necessary soon to consider holding the exhibition where much greater floor space is available. As evidence of the interest taken in the exhibition, it was visited by more than 16,000 people during the three days it was open. The highest pre-war attendance figure was 8,700 .

The development in certain branches of the scientific instrument industry in Britain is indicated in the three discourses delivered at the exhibition*. The first of these discourses, on "The British Optical Industry during the War", was given by Capt. Thomas Martin, deputy director of instrument production, Ministry of Supply. He was mainly concerned with the production of optical equipment for

*A complete report of the first and third of these discourses wil be found in current issues of the Journal of Scientific Instruments, and \& report of the second discourse will appear in the Proceedings of the Physical Society. the Army, but his remarks were often of more general application. He stated that the productive capacity of the optical instrument industry is not less than four times that of pre-war years ; the labour figures, showing an increase from 30,000 in 1939 to 180,000 during the War, suggesting a higher ratio. Typical examples of the quantities of instruments produced during the War were: binoculars 620,000 ; dial sights 32,300 ; clinometers 94,170 ; rangefinders 23,800 ; tank periscopes and episcopes 330,800 ; telescopes 394,460 ; theodolites 5,400 ; microscopes 19,300 , etc.

As Capt. Martin pointed out, many of these instruments had to be suitable for use in tropical and aretic conditions-between temperature limits of $+60^{\circ} \mathrm{C}$. and $-50^{\circ} \mathrm{C}$. These conditions added greatly to the difficulties of the designers and instrument makers. Waterproofing, 'tropicalization', antifungus treatments, etc., were further difficulties which could not always be overcome by modifications of existing types of instruments. Tank periscopes alone required the production of $1,300,000$ prisms, involving the grinding and polishing of 10 acres of glass which, in the finished prisms, weighed about 900 tons. As Capt. Martin remarked : "this is glassworking on a heroic scale". One instrument not manufactured in Britain before the War is the kinetheodolite-a large and complex instrument used to determine the relative positions of an aircraft and shell-bursts, for the purpose of checking the accuracy of anti-aircraft fire.

Of equal importance to the manufacture of good optical instruments is the production of the materials used in their construction. Between the First and Second World Wars, the Government, acting on the advice of the Optical Glass Committee, had provided judicious encouragement to the industry in research and in the production of optical glass. At the outbreak of war, therefore, we were in a favourable position not only to supply the needs of the optical industry in Britain but also to allow a margin for export to our Allies. The sand of Loch Aline, a remote sea loch on the Sound of Mull, has provided the main source of supply not only of the very pure sand for optical glass, but also of less pure grades for chemical glassware, bottle and window glass. The iron content of the purest variety of white sand from this locality is so low as 0.006 per cent. Optical plastics, 'Perspex' and polystyrene have been extensively used in optical instruments, but as yet are not acceptable for precision instruments such as binoculars or telescopes. Work on these lines is proceeding and it would be unwise to predict that glass will always retain its present pre-eminence. Capt. Martin referred to a new process, widely extended during the War, of applying non-reflecting films to optical surfaces-a process generally referred to as 'blooming'. It has assumed great importance in the production of efficient Service instruments containing a large number of air-glass surfaces, for example, submarine periscopes, rangefinders, binoculars and camera lenses where light transmission is of great importance. The process of 'blooming' consists in the distillation in vacuo of a film of quarter wave-length (green light) thickness, of magnesium fluoride or of cryolite, on to the glass surface.

The second discourse was delivered by Sir Edward Appleton, secretary of the Department of Scientific and Industrial Research. His subject was "Radar". He reviewed the history of its development from the pulse technique used in determining the height. 
the ionized layers of the atmosphere, through the stage of detection of aircraft at long ranges to the exact location, range, bearing and height determination for warning and for anti-aircraft gunnery purposes. The latest development is the plan position indicator (P.P.I.) which produces a 'map', on the screen of a cathode ray tube, showing all the radio-reflecting obstacles surrounding the observer, who is assumed to be situated at the centre of the 'map'. The map shows clearly the range and bearing of all objects such as coastline, mountains, high buildings, shipping, aircraft, etc., under any conditions of weather-clear or foggy, night or day. The applications of this device in aerial and sea navigation are of very great import. ance. In his review of radar, Sir Edward spoke of the excellence of the instruments produced by the electrical industry for use by all the Services. Vast numbers of valves, cathode ray tubes and high-grade electrical circuit components were used in these operations, and the electrical industry deserved the highest praise for its efforts. Sir Edward in his coneluding remarks referred to the applications of radar in navigation and in further researches on the upper atmosphere. $\mathrm{He}$ visualized the use of radar echo methods in the near future to obtain data relative to the heights of the mountains and depths of the craters on the moon.

The third discourse was given by Dr. J. C. Swallow, of I.C.I., Ltd. (Plastics Division), who dealt with the subject of "Modern Plastics and Cements". $\mathrm{He}$ referred to the rapid growth of the plastics industry and to the numerous applications of plastics in the design and construction of scientific instruments. The wide variety of mechanical, electrical and optical properties provides a valuable source of material for selection by the instrument designer. Thus the mechanical properties range from rigid to flexible, rubbery or leathery, tough to brittle, transparent to opaque. The electrical insulating properties of some of the plastics are extremely good. "All the plastics are polymers, that is, are composed of macromolecules, or as they are more frequently called, chain molecules with primary valency forces as links, whilst the chains themselves are held together by weaker secondary forces... being polymeric in character the physical properties of plastics can be changed by varying their average chain-length, and the distribution of chain-length round a given average; and we are therefore concerned in many cases with a spectrum of products based on one polymer structure, and subtle differences of properties can be produced by relatively minor changes in manufacturing conditions". Dr. Swallow referred to the usual division of plastics into thermoplastic and thermosetting, and to the sensitiveness of plastics to temperature variations. He dealt in some detail with the use of plastics for constructional purposes; the extensive use of polymethyl methacrylate ('Perspex') as a glazing material in aircraft and in the construction of laboratory apparatus. Polystyrene may be used in much the same way as 'Perspex', but it is particularly valuable when good insulating properties are required and in high-frequency apparatus. Polyvinyl chloride (p.v.c.) is a plastic used as an insulating coating for electrical conductors; it possesses the valuable properties of non-inflammability and a wide range of flexibility. These are only a few of the better-known plastics : the possible variety of these products is almost bewildering. It is obvious that a great future lies ahead in the use of plastics in the scientific instrument industry.
As further evidence of development in the industry, reference could be made in detail to many of the exhibits and demonstrations at the exhibition. Within the limits of this brief survey, however, this is not possible and the reader is recommended to see the exhibition catalogue for further information. As examples of the type of scientific instruments now available may be mentioned a few chosen at random from the catalogue. Thus, in addition to those already mentioned in optics are instruments for colour measurement, high-speed cameras taking 10,000 pictures/second, cameras for aerial surveys, etc. In radio there are numerous radar instruments, air and sea navigational instruments, homing and night-landing equipment for aircraft, new types of valves, such as the magnetron and klystron for centimetre waves, etc. Developments in electronics technique are exemplified by electron microscopes, vacuum evaporation and blooming, cyclotrons (a mechanical model illustrating the principle was shown). Among the many other interesting exhibits may be mentioned sensitive radiation thermopiles, infra-red recording spectrometers, supersonic flaw detectors, samplers for bacteria counts, meters for indicating directly the amount of moisture in grain, cotton, etc., calculating machines which integrate, differentiate, solve mathematical equations or deter. mine the structure factors in X-ray analysis, electrical strain gauges for measuring mechanical strains in complex structures such as the wing of an aeroplane, and so on.

It is almost invidious to pick out particular exhibits in this way, but it must be either that or nothing! Enough has been said to illustrate the rapid developments that have taken place in the British scientific industry during recent years, and to indicate the importance of the industry to progress in research and ultimately to national progress. While appreciating the point made by the President of the Board of Trade that the industry should be in a position to make a sufficient number of instruments for export, it must be definitely realized that from a national point of view it is most important first of all to satisfy the needs of the universities and the research organisations in Great Britain. The industry has served us well during the War; it must be allowed to continue its progress during times of peace.

A. B. Wood.

\section{INFECTIVE HEPATITIS IN FRANCE BY $D_{R}$. JAMES MARSHALL}

TN Great Britain during the War there was a great increase in the incidence of infective hepatitis, and, in the army particularly, of the so-called 'postarsphenamine jaundice'. (This last is almost certainly a virus disease and not directly caused by arsenic ${ }^{1,2}$.) We have suggested in the past that war-time diet, relatively deficient in protein, may have been one reason for this increase ${ }^{3,4}$.

It was known that dietary deficiency was widespread in metropolitan France, particularly in the cities, during the German occupation. It was thought, therefore, that valuable information on the relationship between dietary deficiency and the incidence of hepatitis might be obtained from a study of conditions there. No details about hepatitis during the occupation were available to the French authorities in Britain, and what French medical literature was 